\title{
SER Social
}

NOVA DIREITA, ESTADO E POLÍTICA SOCIAL

Brasília, v. 21, n. 45, julho a dezembro de 2019

\section{A disputa da narrativa conservadora na reforma trabalhista}

\section{The dispute of the conservative narrative in the labor reform}

Nívea Maria Santos Souto Maior ${ }^{1}$

Resumo: O artigo propõe analisar a "reforma" trabalhista como resposta da cultura (neo)conservadora, sendo uma releitura do conservadorismo clássico. Por primeiro, edificam-se as matrizes do pensamento social, desde o surgimento do conservadorismo clássico até a formação do pensamento conservador moderno. O ensaio teórico aborda a gênese do pensamento conservador a partir dos precursores de Edmund Burke até a nova roupagem adquirida no período moderno, a exemplo de Russel Kirk. Na sequência, examina-se o viés conservador e as implicações legislativas de sua influência para a promulgação da reforma trabalhista, com ênfase na presente conjuntura brasileira das contrarreformas do Estado. O estudo, portanto, sinaliza como o capital utilizou sua estratégia de convencimento para desconstruir o corpo normativo que regulamentava o mundo do trabalho, a forma ideológica do discurso governamental dos poderes

1 Advogada, mestranda em Serviço Social pela Universidade Estadual da Paraíba (UEPB/ PPGSS), especialista em Direito do Trabalho pela Universidade Cândido Mendes/RJ, graduada em Direito pela Universidade Estadual da Paraíba (UEPB/PPGSS). 
Legislativo e Executivo na disputa da narrativa conservadora em oposição ao pensamento crítico marxista.

Palavras-chaves: reforma trabalhista; conservadorismo; pensamento social.

Abstract: The text proposes to analyze the labor reform as a response of the (neo) conservative culture, being a rereading of classic conservatism. First, the matrix of social thought is built, from the emergence of classical conservatism to the formation of modern conservative thinking. The theoretical essay approaches the genesis of conservative thinking from the precursors of Edmund Burke to the new clothing acquired in the modern period such as Russell Kirk. In a sequel, we examine the conservative bias and the legislative implications of its influence for the enactment of the labor reform, with emphasis on the present Brazilian conjuncture of counter-reforms of the State. The study, therefore, shows how capital used its convincing strategy to deconstruct the normative body that regulated the world of work, the ideological form of the governmental discourse of the legislative and executive powers in the contest of the conservative narrative in opposition to the critical marxist thought.

Keywords: labor reform; conservatism; social thought.

\section{Introdução}

Hodiernamente, a classe trabalhadora se encontra numa espécie de neoescravidão e retrocesso da sua condição humana, tudo em razão do rebaixamento dos direitos sociais conquistados e da agudização da crise capitalista. A sociedade brasileira tem contradições acumuladas há mais de 500 anos por não resolver problemas fundamentais, tal como o trabalho decente.

Constata-se que não existe a possibilidade de trabalho emancipador no capitalismo, o trabalho assalariado está atrelado à superacumulação e intrínseca ao empobrecimento do proletariado; isto não é só teoria, é a lógica do cotidiano, a realidade concreta. Desta feita, a resolução da barbárie implica necessariamente na adoção de um pensamento crítico sobre a exaustão do poder civilizador do capitalismo.

Apenas a adoção de um pensamento reacionário é capaz de uma mudança estrutural para provocar a revolução anti-imperialista. As premissas acima são imperativas para entender que o pensamento conservador foi determinante para o atual estado das coisas, em 
virtude de existir uma relação direta da crise capitalista com a ascensão do pensamento conservador no Brasil.

O conservadorismo não é uma teoria, é uma ideologia, ou seja, trata-se de um conjunto sintético de ideias que consegue orientar as ações de uma determinada classe, no caso em específico a classe dominante. A legislação trabalhista acompanha umbilicalmente a reestruturação da produção capitalista, no qual o Direito se impõe como forma necessária para tornar o trabalho assalariado sua principal mercadoria.

Tanto o Estado como o direito não são elementos neutros, muito menos técnicos. As leis que são instituídas por estes entes têm uma razão específica de ser na própria relação capitalista. O modo de produção capitalista abrange também um modo capitalista de pensar para expressar a ideologia da classe dominante, como forma de consenso social. Com apropriação, Iamamoto (2014, p. 116) esclarece que:

O controle social e a difusão da ideologia dominante constituem recursos especiais, complementando outras maneiras de pressão social com base na violência, para a obtenção de consenso social. Importa ressaltar que a ideologia dominante é um meio de obtenção de consentimento dos dominados e oprimidos socialmente, adaptando-os à ordem vigente. Em outros termos: a difusão e a reprodução da ideologia é uma das formas de exercício do controle social.

Por isso, a finalidade deste estudo é realizar um ensaio teórico sobre a gênese do pensamento conservador e a nova roupagem adquirida no período moderno, demonstrando ainda o viés conservador da Lei Federal n ${ }^{0}$ 13.467/2017, alcunhada de "reforma" trabalhista, ${ }^{2}$ como suposta e fenomênica condição para salvar a economia brasileira.

2 Os termos “reforma” trabalhista, contrarreforma trabalhista e deforma trabalhista são tomados como sinônimos neste artigo. A razão é a tentativa subliminar de associar a ideia de aprimoramento da situação legislativa, quando na realidade ao invés de melhorar, houve uma piora nos direitos sociais. As contrarreformas, regra geral, rebaixam marcos legais já conquistados em determinado momento pela luta de classe no país. 
Não é mera coincidência que os principais defensores da contrarreforma trabalhista no Brasil sejam as instituições representativas do empresariado, como a Confederação Nacional da Indústria (CNI), a Federação das Indústrias do Estado do Rio de Janeiro (Firjan), a Federação das Indústrias do Estado de São Paulo (Fiesp), entre outras. Para elas os direitos são entraves para garantia dos lucros na ótica capitalista, quando, na verdade, o próprio direito é um complexo social determinado que age como limitador das condições de trabalho.

Este acelerado processo de conservadorismo e reacionarismo no Brasil objetiva calar a crítica em todas as esferas sociais, solicitando assim um indivíduo silencioso, uma classe proletária incapaz de reagir aos ditames do grande capital, a ponto de se configurar como um "pensamento único". ${ }^{3}$

Partindo desta breve apresentação, será demonstrado que a narrativa conservadora, elaborada no pensamento do tradicionalismo, defende a adoção de reformas sociais que não alterem a estrutura da sociedade contemporânea. Enquanto os conservadores narram a “reforma” trabalhista como modernização da legislação brasileira, os materialistas históricos evidenciam a involução da resistência organizada dos trabalhadores; sendo válido reafirmar a célebre frase do escritor uruguaio Eduardo Galeno: "A primeira condição para modificar a realidade consiste em conhecê-la”.

\section{As matrizes do pensamento social e o surgimento do conservadorismo}

É decisivo, para a compreensão da atual configuração do conservadorismo, apreender primeiro o seu surgimento e as principais matrizes do pensamento social. As duas grandes matrizes nasceram no mesmo episódio, qual seja, a Revolução Francesa, que foi a fase da decadência do antigo regime absolutista; enquanto o positivismo justificava a sociedade capitalista, o marxismo a contestava.

3 O pensamento único elimina as zonas de resistência, transformando os seres em consciências anestesiadas, por isso tende a se tornar cada vez mais único e cada vez menos um pensamento. 
Para Löwy (1994, p. 19): “O positivismo moderno nasceu como um legítimo descendente da filosofia do iluminismo". Existe um marco cronológico importante a ser registrado, nos séculos XVII e seguinte: o positivismo era apenas uma utopia revolucionária (período de ascensão da burguesia), marcado pelas ideias formuladas por Condorcet e Saint Simon; enquanto que, no século XIX, tornouse uma ideologia conservadora atrelada com a ordem burguesa.

O positivismo postula as relações aparentes dos fatos, encurta a visão teórica apenas no empírico no que pode ser verificado e experimentado. Provavelmente tal perspectiva seja porque Augusto Comte (pai do positivismo) foi influenciado pela metafísica, no qual defende a obtenção do conhecimento somente por meio da experiência. O problema filosófico desta corrente é a fragmentação, cancelando a compreensão da totalidade.

Em contrapartida, o marxismo tem por objeto a gênese, desenvolvimento, consolidação e crise da sociedade burguesa. Apesar de ter sido objeto também para outros filósofos como Durkheim e Weber, ${ }^{4}$ a diferença do marxismo é a perspectiva política e metodológica (o método crítico-dialético, conhecido como materialismo histórico).

Para Marx, a teoria é uma reprodução (reconstrução) ideal que expressa algo ontologicamente anterior, a aparência dos fenômenos é apenas o ponto de partida da dinâmica estrutural, buscando entender os fatos em sua essência, diferenciando-se assim substancialmente do positivismo.

Além das matrizes antes apontadas, o positivismo incentivou o sistema de ideias conservadoras, o conservadorismo clássico igualmente remete sua gênese pós-1789 e teve como principal fundador o filósofo irlandês Edmund Burke, cuja ideologia defen-

\footnotetext{
4 Interessante registrar que o sociólogo marxista Michael Löwy enquadra Weber como positivista, porque ele reivindica uma neutralidade que, por sua vez, é um axioma do positivismo; para a corrente positivista, a vida social é regida por leis naturais universais e invariáveis como, por exemplo, a naturalização da pobreza. Outro exemplo bastante atual é o movimento "Escola sem Partido", fundamentado de que o conhecimento é neutro, construído a partir da observação de fatos. Já para o marxismo, não existe neutralidade, a verdade é uma construção histórica e depende da disputa de forças entre as classes sociais que produzem o conhecimento.
} 
dia um pensamento restaurador e antiburgês. Não se trata de uma teoria, mas de uma sistematização de ideias como, por exemplo, a naturalização da desigualdade (SOUZA, 2015). Desta feita, o conservadorismo nasceu como forma reacionária da aristocracia diante da burguesia até então como classe social revolucionária, marcando o fim do período medieval.

Burke influenciou muitos conservadores da atualidade, dentre eles Russel Kirk, na obra Política da Prudência (2014) e movimentos de extrema direita. Ele usava a Revolução Gloriosa (1688), como modelo a ser seguido no qual projetava o Estado e a sociedade como uma ordem natural e divinamente estabelecida; em contrapartida este teórico não economizou críticas à Revolução Francesa por representar uma ruptura violenta com as heranças da tradição. ${ }^{5}$

Burke quer a continuidade do desenvolvimento econômico capitalista sem a ruptura com as instituições sociais pré-capitalistas (o privilégio da família, as corporações, o protagonismo público-temporal da Igreja, a hierarquia social cristalizada etc.). E considera que a Revolução é a excrescência desnecessária que efetiva essa ruptura. Sinteticamente, poderse-ia afirmar que Burke deseja o capitalismo sem a Modernidade. (ESCORSIM NETTO, 2011, p. 45).

Ademais, o conservadorismo teve um conjunto de outros pensadores, a exemplo de Alexis de Tocqueville e Emile Durkheim, cujas formulações serviram de passagem do pensamento conservador clássico para o moderno (neoconservadorismo); no primeiro estágio, o conservadorismo era antagônico ao liberalismo, mas atualmente muito se aproximam e corriqueiramente são tomados como sinônimos.

5 A respeito de Burke entender que processos revolucionários precisam ser combatidos, cabe interessante paralelo: o Golpe de Estado (1964) ocorrido no Brasil foi intitulado pelos militares como "processo de aprimoramento". Aliado ao governo ditatorial houve um pacto conservador, naquela época, para modificar algumas normas trabalhistas como, por exemplo, a substituição da estabilidade decenal pelo Fundo de Garantia por Tempo de Serviço (FGTS). O traço histórico da presente análise é fundamental para entender ontologicamente a realidade dos dias atuais. 
Esta transformação é corretamente explicada por Escorsim Netto (2011, p. 49-50):

[...] nos conservadores que trabalham nas condições pós-48, com a evidência da inviabilidade da restauração, o conservadorismo passa a expressar o repúdio a qualquer revolução - ou seja, o pensamento conservador passa a se definir explicitamente como contrarrevolucionário. É assim que ele tem substantivamente mudada a sua função social: de instrumento ideal de luta antiburguesa, converte-se em subsidiário da defesa burguesa contra o novo protagonista revolucionário, o proletariado. (grifo nosso).

Assim, é inteligível rematar que o conservadorismo moderno mudou o protagonista do estágio clássico: se antes a odiosa era a burguesia revolucionária, passa-se a funcionalizar sua oposição à classe operária, e o ano de 1848 foi incisivo para a irrupção deste novo sujeito histórico.

[...] Isso significa dizer que o projeto da Modernidade foi útil à burguesia enquanto seus interesses ainda eram expressões universais. A partir do momento em que transmutaram evidenciando claramente seu projeto particular de classe dominante, os pilares centrais da modernidade e seu desenvolvimento em direção à emancipação humana e à razão dialética passam a representar uma ameaça à sua forma de organização produtiva. (SANTOS, 2005, p. 39).

Por derradeiro, pontua-se o traço conservador também no pensamento pós-moderno, sendo conveniente pontuar mais esta matriz teórica que é o Pós-Modernismo, cuja origem brotou no final da década de 70 como alternativa ao modernismo e, em especial, como substituto das ciências sociais, com ênfase ao texto A condição pós-moderna, de Jean-François Lyotard, que foi um desbravador do pensamento pós-moderno.

Dentre inúmeras rupturas, é primordial destacar que, na perspectiva pós-moderna, a questão do saber é tomada com fins exclusivamente instrumentais (mecanicista) e, portanto, numa lógica de consumo, desembocando em mercadoria e, até mesmo, no irracionalismo. Logo, o saber no pensamento pós-moderno perde o valor 
de uso e mantém apenas seu valor de troca, rememorando o sentido mannheimiano ${ }^{6}$ que reivindicava o conservadorismo como um estilo de pensamento, tão presente na contemporaneidade.

Diante das matrizes supracitadas, observa-se também a crucial diferença no tocante à centralidade do trabalho na dinâmica da sociedade capitalista; para Marx, o discurso deve ser centrado na dialética do trabalho enquanto categoria fundante do ser social; enquanto que nas ideologias pós-modernas o trabalho não constituiria mais o eixo da vida social e, para tanto, se alcunha como "fim da sociedade do trabalho" defendida por Claus Offe e Habermas.

Em rebate, o deslocamento da centralidade do trabalho para dar centralidade a outro eixo (a exemplo da linguagem - esfera comunicacional) não será capaz de mudar a realidade concreta, pois esta crise de paradigma é uma tentativa de fragmentação e dispersão da classe trabalhadora. Prova cabal disto são os neologismos tais como os termos cooperativismo e empreendedorismo que são tão somente ressignificações conservadoras que mascaram as novas gerações de trabalhadores.

É defensável acreditar que as racionalidades contrárias à matriz crítico-dialética reivindicam discursos carentes de determinações ontológicas cruciais para a apreensão da totalidade da visão social, e isto invade a reflexão sobre a conjuntura brasileira e as contrarreformas do Estado, a seguir delineadas.

\section{A "reforma” trabalhista e seu viés conservador}

Em noções abreviadíssimas, para apreender o atual regime político e seu respectivo projeto ultraconservador, é preciso recorrer à historicidade dos fatos, ${ }^{7}$ e nesse ínterim ciente da impossibilidade do presente estudo dar conta de todo o resgate mais aprofundado do projeto neoliberal, o recorte histórico será demarcado

6 Conveniente registrar que Karl Mannheim inicialmente passou por forte influência marxista, porém ele desertou desta primeira ideia por não acreditar que fossem necessários meios revolucionários para atingir uma sociedade melhor.

7 Em sentido contrário, a narrativa conservadora se vale do presentismo como ferramenta de sua decadência ideológica, buscando a desistoricização do tempo presente. 
a partir das Jornadas de Junho de 2013 cujo evento foi um insight para o golpe parlamentar.

A reivindicação inicial era o aumento das passagens de ônibus em São Paulo (manifestação dos 20 centavos) passando posteriormente a ser um protesto sobre diversos temas (à semelhança de um boneco de Judas), desde a má qualidade dos serviços públicos até a indignação com a corrupção política, com um peculiar repúdio à presença de bandeiras de partidos políticos, gerando um clima político propício para descontentamento com o governo petista.

Na verdade, Junho de 2013 inaugurou o colapso do consentimento passivo das classes subalternas ao projeto de governo lulista. A despeito de titubeante, o apoio do proletariado precarizado ainda garantiu a vitória de Dilma Rousseff no segundo turno das eleições de 2014. No entanto, esse apoio estava condicionado à manutenção do emprego formal, ainda que de baixa qualidade. O aumento da taxa de desemprego selou finalmente o divórcio litigioso, anunciado em 2013, do precariado urbano com o lulismo. O proletariado sindicalmente organizado ainda não abandonou seus representantes lulistas, mas, a depender da magnitude da crise, poderá, sem dúvida, fazê-lo em breve. (BRAGA, 2016, p. 90) (grifo nosso).

E assim foi feito. O pacto conciliatório ${ }^{8}$ entre a classe trabalhadora e a gestão burguesa do governo Dilma foi rompido em virtude do não atendimento dos ajustes neoliberais ortodoxos exigidos pelos principais grupos empresariais do país. Naquela ocasião, não houve correlação de forças, simplesmente uma apatia e desconfiança dos setores populares que perduram até hoje.

O esgotamento definitivo pode ser comprovado no dia 17/04/2016, data em que a Câmara dos Deputados aprovou o seguimento do processo de impeachment de Dilma, e os parlamentares justificaram seus votos “em nome de Deus, ${ }^{9}$ na moralidade e na famí-

\footnotetext{
8 A coesão social é uma fala não marxista. Conciliação de classes só interessa para beneficiar o capital.

9 Para o conservadorismo, a laicização é deletéria, a religião deve estar conectada ao Estado.
} 
lia”, uma fidedigna exibição de valores conservadores e reavivando a aproximação entre Igreja e Estado.

A ascensão de Michel Temer à Presidência sinalizou o início de um "neoliberalismo ortodoxo", com a adoção de medidas neoliberais mais rígidas, de natureza irrestrita para efetivar políticas austeras em favor da classe capitalista. E apesar de ser um processo aberto da história, é notório que os direitos sociais - os alicerces da cidadania brasileira - embora fixados em leis, são alvos de ataque, uma vez implementados já se tornam alvo de contrarreformas.

Neste ambiente, o Estado ultraconservador passa a focar suas ações na diminuição das políticas sociais e no consequente esvaziamento dos direitos sociais previstos na Constituição Federal de 1988, materializado no novo regime fiscal (Emenda Constitucional no 95/2016 ${ }^{10}$ ), na “reforma” do ensino médio (Lei no 13.415/2017), na contrarreforma da previdência (ainda em tramitação legislativa - PECs n $n^{0}$ 287/2016 e no 06/2019) e no presente objeto de estudo: a contrarreforma trabalhista. (Lei no 13.467/2017).

Na atualidade, a população brasileira, particularmente a classe trabalhadora, vem enfrentando a maior ofensiva da história deste país contra o conjunto das conquistas civilizatórias de nosso Estado. Tal argumento pode ser evidenciado nas diversificadas e inúmeras medidas tomadas, desde a posse de Michel Temer: autorização para privatização de aquíferos, avanço no processo de privatização da Petrobras, aprovação de reforma trabalhista, aprovação de teto de gastos por 20 anos, encaminhamento de projeto de reforma da previdência social draconiano, entre outros. Todas essas proposições levaram autores a afirmar que o conjunto de tais medidas não configuram simplesmente um programa de ajuste, mas um austericídio. (SOARES, 2018, p. 24-25).

10 O congelamento dos gastos primários por longos 20 anos, afeta diretamente nos serviços básicos à população e aumenta ainda mais a concentração de renda. O Instituto de Pesquisa Econômica Aplicada (Ipea) realizou um estudo sobre o impacto deste ajuste fiscal na Assistência Social e estima-se a queda orçamentária (perdas acumuladas) em 54\% no ano de 2036. Disponível em: <https://www.abrasco.org.br/site/wp-content/uploads/2016/09/nt_27_IPEA_regime_fiscal_assistencia_social.pdf $>$. Acesso em: $12 / 02 / 2019$. 
Em sequência, Souza (2015, p. 213) faz pertinente mediação entre o conservadorismo moderno e a implementação da agenda neoliberal, a saber:

[...] os conservadores pareciam menos reativos às mudanças institucionais no interior do capitalismo. Saiu fortalecido o argumento de que, se o capitalismo expressa a natureza comercial nos homens, as reformas que servirem à ampliação das liberdades de mercado estarão de acordo com essa natureza (COUTINHO, 2014). Isso implica: desregulamentação, liberalização, privatizações e reformas tributária, fiscal, monetária, trabalhista, entre outros encaminhamentos político-institucionais. Dessa maneira, a primeira conciliação do conservadorismo com o capitalismo, encontrada na sociologia funcional-positivista, foi complementada com a composição (neoliberal) política e institucional de Thatcher. Desta feita, para preservar o sistema estabelecido, há de serem assumidas as reformas (institucionais) necessárias. (grifo nosso).

Primeiramente, a reforma trabalhista: trata-se de uma lei sancionada por um presidente com o maior índice de rejeição popular da história, ${ }^{11}$ com o aval do Congresso Nacional, ${ }^{12}$ além das manipulações produzidas pela grande mídia ${ }^{13}$ (aparelhos privados de hegemonia) provocando, via de consequência, a desinformação da sociedade sobre os reais fatos que embalaram a aprovação da reforma trabalhista, qual seja: a flexibilização e a precarização do trabalho assalariado.

11 As avaliações apontam que o Governo Temer tem em média aprovação de 4\% e reprovação de 79\%. Informação obtida em: <https://www.valor.com.br/politica/5751439/ aprovacao-do-governo-temer-cai-para-27-aponta-cntmda>. Acesso em: 13/09/2018.

12 A contrarreforma trabalhista teve uma tramitação legislativa em tempo recorde de aproximadamente seis meses, com a ausência de debate democrático e a inexistência do poder revisor do Senado Federal.

13 Em pesquisa realizada no ano de 2015 foi levantado o seguinte dado: 73\% dos brasileiros tem como única fonte de informação apenas a televisão. Isto provoca também uma imagem distorcida das leis trabalhistas. Informação obtida em: <http://prolivro.org.br/ home/images/2016/Pesquisa_Retratos_da_Leitura_no_Brasil_-_2015.pdf $>$. Acesso em: 13/09/2018. 
Ademais, outra inverdade merece ser denunciada, que é a suposta velhice da CLT cujo conteúdo estaria obsoleto, quando na realidade esta legislação foi paulatinamente sendo atualizada; estudos $^{14}$ apontam que dos 921 artigos que constavam no diploma celetista no ano de 1943, apenas 255 artigos não foram revogados ou alterados de maneira expressa por leis posteriores, editadas nos mais diversos governos. Veja que, no senso comum, o conservadorismo se aproveita de frases prontas, tal como a senilidade de uma lei, que não explicam nada e apenas cristalizam muitos preconceitos (falsas consciências).

E em meio a esta polêmica lei surge a expressão de modernização, haja vista que como aparentemente a CLT estaria ultrapassada, a inovação legislativa teve como justificativa a ideia de "modernização" que, por sua vez, se liga à ideia de melhorar aquilo que lhe antecedia.

Todavia, o que se verifica é diametralmente o oposto. A contradição central do pensamento moderno reside exatamente no conflito entre sua proposta revolucionária e sua prática conservadora. Houve a falsa retórica de aumentar o número de empregos formais e salvar o país de uma crise econômica, mas, o que de fato ocorreu, foi “[...] com a reforma trabalhista, o capital aumenta o seu poder para ditar o Direito e, ao mesmo tempo e como consequência, se livrar dos seus limites, tudo isto, em nome da liberdade de contratação, que não passa de uma ilusão”. (ALMEIDA, 2017, p. 220).

Esta novidade legislativa inaugura novas formas de contratação do trabalhador, corroendo sua renda salarial, a exemplo do trabalho intermitente no qual o operário fica à espera do chamado do empregador. Esta alternância de períodos de prestação de serviços e de inatividade também é conhecida como “jornada zero hora”, que é uma forma de estrangular ao máximo os poros da jornada de trabalho e proporcionar menores custos para o senhoril; isto esmaga a renda do trabalhador, haja vista o pagamento apenas das horas trabalha-

14 Disponível em: <https://www.jorgesoutomaior.com/blog/i-a-clt-e-velha>. Acesso em: 25/07/2018. 
das sem a garantia de uma estabilidade salarial prevista no contrato típico de trabalho.

Observa-se que a tendência atual da massa salarial do trabalhador é ser oriunda da subproletarização tardia, constituída pelos trabalhadores assalariados em tempo parcial, temporários ou subcontratados. Esta última abrange os terceirizados, sendo uma categoria em particular que mais sofre no ambiente de trabalho e apresenta vínculos com baixa remuneração em relação àqueles diretamente contratados.

Logo, a contrarreforma trabalhista gera insegurança e empobrecimento para os trabalhadores, uma situação que não lhes garante sequer o mínimo para que possa manter sua sobrevivência e de sua família, sendo inevitável o endividamento e aumento da precarização de vida da classe trabalhadora.

Reitera-se também a cultura do empreendedorismo que não é uma demanda do trabalho, mas sim uma necessidade do capital. Troca-se a proteção social por uma promessa de liberdade (autonomia). Um protótipo deste trabalho é o aplicativo Uber, no qual o motorista seria aparentemente um gerente de si próprio, quando de fato ocorre um trabalho subordinado com a descentralização total da execução do serviço, uma burla trabalhista disfarçada de autogestão.

Ironicamente, o empreendedor é chamado a experimentar a mesma lógica que move os capitalistas: ganhar dinheiro com o trabalho alheio. Dados os parcos recursos do empreendedor, é como se lhe fosse oferecida uma ínfima porção de uma poderosa droga que garante prazer imediato e, portanto, vicia, mas ele não dispõe de recursos para manter o vício. Ante a impossibilidade de consumir a droga na medida das sensações desejadas, o empreendedor, numa luta inglória, aplica toda a sua força de trabalho, contrai dívidas e, por vezes, ocupa os membros da família, na tentativa de alcançar o que lhe fora prometido. Contudo, na maioria dos casos, só consegue contribuir para a precarização do trabalho, o seu e o de outros trabalhadores. (TAVARES, 2018, p. 119). 
A precarização, objeto ora em análise, passa a ser naturalizada e tida como possível solução para o desemprego no país, mascarando os mecanismos de exploração e relações de desproteção social: trabalho sem carteira assinada, precário e desprotegido (ANTUNES, 2006). Assim, no caminho em que se registram índices alarmantes do desemprego no país, encontra-se também a redução do padrão de vida dos que conseguem se manter nos postos de trabalho.

Mais um aspecto conservador da contrarreforma é o axioma "negociado sob o legislado"15 que nada mais é do que a retomada de poder em favor da classe patronal e pelo capital, com as empresas tendo ampla liberdade para negociar diretamente com os trabalhadores ou sindicatos fragilizados. Na realidade, a única liberdade inaugurada pela lei foi a do trabalhador vender sua força de trabalho aquém do estabelecido pela lei.

A respeito de uma suposta igualdade no tema negociado sob o legislado, Pachukanis expõe que tal empate fica apenas no plano abstrato da sociabilidade burguesa. O Direito - entendido como um conjunto de leis - resta caracterizado "[...] como a forma jurídica que representa a forma mercantil capitalista” (SANTOS, 2017, p. 408). Nesta direção, é possível verificar a equiparação exclusivamente formal do trabalhador como um homem livre (um sujeito de direitos) capaz individualmente de negociar suas condições laborais.

Reafirma-se que, para a grande massa de trabalhadores, inseridos ou não no mercado de trabalho, as mudanças implementadas na legislação trabalhista, significam a ampliação do nosso velho padrão despótico de relações de trabalho (COSTA, 2005) com forte tendência a aumentar os níveis de desemprego que sempre apresentaram altos índices no contexto brasileiro.

Dadas as características autoritárias, excludentes e desiguais que marcaram a sociedade brasileira e o sistema de relações de trabalho no país, o desencadear dessas "reformas” põe em foco expressões da questão social muito mais complexas do que se possa mensurar.

15 Significa dizer que as convenções e acordos coletivos poderão prevalecer sobre a legislação. Assim, os sindicatos e as empresas podem negociar condições de trabalho diferentes das previstas em lei, mas não necessariamente num patamar melhor para os trabalhadores. 
Nesse sentido, o Estado burguês não tem como objetivo a resolução das refrações da questão social, mas propiciar a emergência de novas expressões da "questão social", a exemplo da contrarreforma trabalhista que se apresenta como função estatal para garantir a reprodução ampliada do capital. Desta feita, o projeto ultraconservador do governo Temer agudiza várias expressões da questão social e configura-se claramente como uma reação burguesa conservadora de cunho regressivo ao proletariado.

\section{Considerações finais}

A intenção do presente texto foi apresentar um panorama da disputa dogmática, desmistificando a descrição sociológica que melhor consegue explicar o mundo contemporâneo, em especial as mudanças no mundo do trabalho. Na luta de classes, não existe empate, ${ }^{16}$ já que a classe trabalhadora se fragmenta e via de consequência ocorre a conservação da ordem (das coisas exatamente como elas estão), os direitos surrupiados na "reforma" trabalhista expressam o nível das contradições inerentes ao capitalismo.

O viés conservador da contrarreforma trabalhista implica numa narrativa hegemônica (leia-se: um consórcio formado pelas elites do país, o Poder Legislativo e o oligopólio midiático), sendo necessária a produção de um conhecimento insurgente para alcançar uma irmanação dos trabalhadores a ponto de fortalecer as condições de sua emancipação.

São tempos difíceis para a razão dialética frente ao atual vazio ideológico, em que ocorre um mascaramento das relações concretas de forma a interditar qualquer espécie de análise crítica. O pensamento conservador busca o que é útil aos interesses do capital, de

16 Trata-se da campanha promovida pelo conjunto CFSS/CRESS pelo dia 15 de maio de 2018 (dia do/a assistente social) e teve como tema "Nossa escolha é a resistência: somos classe trabalhadora!”. Isso posto, já que “Em tempos de ataque aos direitos da população, nossa escolha é a resistência! Em tempos de avanços da onda conservadora e reacionária, nossa escolha é a resistência! Em tempos de desmontes subsequentes das políticas sociais, nossa escolha é a resistência! Porque somos assistentes sociais, somos classe trabalhadora!”. (CFESS, 2018). 
modo que os proletários não se identificam mais como classe e perdem o poder da auto-organização na busca por direitos.

Eis os fatos que a narrativa conservadora nos impede de obter o seu real alcance: vive-se no Brasil a pior crise de toda a história republicana, numa espécie de esquizofrenia social. Um período de devastação profunda em todos os aspectos da vida social (militarização, banalização, miséria e fome) e, em especial, a perda da perspectiva de um futuro digno ao trabalhador (ratificada pelo aumento crescente dos desalentados).

Enfim, abre-se na atualidade um desafio para o efetivo combate ao movimento neofacista. Urge para as lutas sociais e o movimento popular repensar um novo projeto de futuro para a sociedade brasileira.

Artigo submetido em 26/02/2019

Aceito para publicação em 22/04/2019

\section{Referências}

ALMEIDA, Cleber Lúcio de. A reforma trabalhista e o acesso à justiça. In: FELICIANO, Guilherme Guimarães; TREVISO, Marco Aurélio Marsiglia, FONTES, Saulo Tarcísio de Carvalho (Orgs.). Reforma trabalhista: visão, compreensão e crítica. São Paulo: LTr, 2017. p. 215-223.

ANTUNES, Ricardo. Adeus ao trabalho? Ensaio sobre as metamorfoses e a centralidade do mundo do trabalho. 11. ed. São Paulo: Cortez, 2006.

BRAGA, Ruy. Terra em transe: o fim do lulismo e o retorno da luta de classes. In: LOUREIRO, Isabel; SINGER, André. As contradições do lulismo: a que ponto chegamos? 1. ed. São Paulo: Boitempo, 2016, p. 55-92.

COSTA, Márcia da Silva. O sistema de relações de trabalho no Brasil: alguns traços históricos e sua precarização atual. Revista Brasileira de Ciências Sociais, v. 20, n. 59, p. 111-131, out./2005. Disponível: <http://www.scielo.br/ scielo.php?script=sci_arttext\&pid=S0102-69092005000300008\&lng=en\&nrm=i so>. Acesso em: 17/02/2019.

ESCORSIM NETTO, Leila. O conservadorismo clássico: elementos de caracterização e crítica. São Paulo: Cortez, 2011.

IAMAMOTO, Marilda Villela; CARVALHO, Raul. Relações sociais e serviço social no Brasil: esboço de uma interpretação histórico-metodológica. 41. ed. São Paulo: Cortez, 2014. 
LÖWY, Michael. As aventuras de Karl Marx contra o Barão de Münchhausen: marxismo e o positivismo na sociologia do conhecimento. 5. ed. São Paulo: Cortez, 1994.

SANTOS, Josiane Soares. Pós-modernidade, neoconservadorismo e Serviço Social. Temporalis, ano V, n. 10, p. 29-50, jul.-dez./2005.

SANTOS, Amanda Cataldo de Souza Tilio dos. Resenha da Obra 'Teoria Geral do Direito e Marxismo’ de E. B. Pachukanis. Revista da Faculdade de Direito do Sul de Minas, v. 33, n. 1, p. 407-430, jan.-jun./2017.

SOARES, Raquel Cavalcante. Governo Temer e contrarreforma na política de saúde: a inviabilização do SUS. Argumentum, v. 10, n.1, p. 24-000, jan.abr./2018. Disponível em: http://www.periodicos.ufes.br/argumentum/article/ viewFile/19496/13178. Acesso em: 10/02/2019.

SOUZA, Jamerson Murillo Anunciação de. O conservadorismo moderno: esboço para uma aproximação. Serviço Social \& Sociedade, n. 122, p. 199-223, 2015.

TAVARES, Maria Augusta. O empreendedorismo à luz da tradição marxista. Revista em Pauta, v. 16, p. 107-121, 2018. 